\title{
A HISTÓRIA DA MATEMÁTICA COMO INSTRUMENTO DE ENSINO E APRENDIZAGEM NA EDUCAÇÃO BÁSICA
}

\section{THE HISTORY OF MATHEMATICS AS A THEACHING AND LEARNING INSTRUMENT IN BASIC EDUCATION}

\author{
Andréia Nunes dos Santos ${ }^{1}$ \\ Instituto Federal de Educação, Ciência e Tecnologia do Ceará Campus Crateús \\ Juciane de Sousa ${ }^{2}$ \\ Instituto Federal de Educação, Ciência e Tecnologia do Ceará Campus Crateús
}

\section{Resumo}

O presente trabalho é fruto de uma pesquisa que encontra-se em estágio inicial e apresenta como pressuposto verificar o uso da história da matemática como uma estratégia metodológica, de maneira a constituir o ensino da disciplina de matemática, além de desenvolver nos discentes a capacidade de ordenação histórica das descobertas matemática e como se deu o desenvolvimento de conceitos, fórmulas e aplicabilidades ao longo do tempo, inseridas como meio de motivação nas aulas de Matemática. Compreendemos que ao relacionarem os conteúdos matemáticos com o cotidiano, os alunos podem despertar maior interesse pela disciplina, e com isso tornar a aprendizagem mais significativa. Diante disso, com o propósito de estabelecer uma discussão teórico reflexiva, partimos da seguinte questão que que norteará a nossa investigação: Como inserir tópicos da história da Matemática no ensino, de maneira articulada com as outras áreas do conhecimento possibilitando oportunidades de uma aprendizagem mais significativa em Matemática? Assim, objetivamos possibilitar ao trabalho de docentes de Matemática, reflexões em torno de um ensino pautado na implementação da história da Matemática como estratégia metodológica na Educação Básica. Como metodologia, a pesquisa insere-se em uma abordagem qualitativa e está pautada em uma revisão de literatura acerca da utilização da história da matemática em sala de aula. Ao pesquisarmos autores como Miorim (2005), Brasil (1998), D'Ambrosio (2012), Lopes \& Alves (2014) em que os mesmos defendem a utilização da história da matemática como estratégia de ensino em sala de aula. Através do uso dessa metodologia de ensino, é possível que os docentes diversifiquem os recursos para abordar o assunto na sala de aula. Consideramos ainda que a utilização da história da matemática poderá desempenhar muitas outras funções, como o desempenho de atitudes e valores mais favoráveis diante do conhecimento matemático, o resgate da própria identidade, a sugestão de abordagens diferenciadas e a compreensão de obstáculos encontrados pelos alunos. Em âmbito geral, os discentes consideram a matemática uma disciplina muito teórica, complexa e que não possui nenhuma relação com as outras

\footnotetext{
1 andreian765@gmail.com

2 jucianedes@gmail.com
} 
áreas do conhecimento. Em nosso estudo, a história da matemática também configura-se como tendência de ensino em educação matemática que está se propagando como um subsídio metodológico. Como resultados esperados, pretendemos desmistificar a ideia de que matemática é uma ciência puramente abstrata e isolada das demais áreas, e oferecer aos professores uma estratégia que permita que eles realizem uma interligação entre história e Matemática. Vale ressaltar que é de suma importância que todo aluno tenha conhecimento da história do conteúdo que está sendo abordado em sala de aula, fazendo uma ligação cultural entre duas áreas do conhecimento, para compreender a importância de haver uma articulação entre elas.

Palavras-chave: História da Matemática; Ensino de Matemática; Formação de Professores

\section{Abstract}

The present work is the result of a research that is at an early stage and presents as presupposition to verify the use of the history of mathematics as a methodological strategy, in order to constitute the teaching of the mathematics discipline, besides developing in students the ability to historical ordering of mathematical discoveries and the development of concepts, formulas and applicability over time, inserted as a means of motivation in mathematics classes. We understand that by relating mathematical content to everyday life, students may arouse greater interest in the subject, and thus make learning more meaningful. Given this, with the purpose of establishing a reflexive theoretical discussion, we start from the following question that will guide our research: How to insert topics from the history of mathematics in teaching, in articulation with the other areas of knowledge, providing opportunities for more meaningful learning. in math? Thus, we aim to enable the work of mathematics teachers, reflections around a teaching based on the implementation of the history of mathematics as a methodological strategy in Basic Education. As a methodology, the research is part of a qualitative approach and is based on a literature review about the use of the history of mathematics in the classroom. When researching authors such as Miorim (2005), Brazil (1998), D'Ambrosio (2012), Lopes \& Alves (2014) in which they defend the use of the history of mathematics as a strategy for classroom teaching. Through the use of this teaching methodology, it is possible for teachers to diversify resources to address the subject in the classroom. We also consider that the use of the history of mathematics may perform many other functions, such as the performance of more favorable attitudes and values in the face of mathematical knowledge, the recovery of one's own identity, the suggestion of different approaches and the understanding of obstacles encountered by students. In general, students consider mathematics a very theoretical discipline, complex and unrelated to other areas of knowledge. In our study, the history of mathematics also appears as a teaching trend in mathematics education that is spreading as a methodological support. As expected results, we intend to demystify the idea that mathematics is a purely abstract science isolated from other areas, and offer teachers a strategy that allows them to make a connection between history and mathematics. It is noteworthy that it is extremely important that every student has knowledge of the history of the content being addressed in the classroom, making a cultural connection between two areas of knowledge, to understand the importance of having an articulation between them.

Keywords: History of Mathematics; Mathematics teaching; Teacher training 


\section{Introdução}

A história da matemática é o resultado de práticas desenvolvidas pelo processo de desenvolvimento da humanidade e tem como objetivo na disciplina de Matemática possibilitar uma articulação com o abstrato, assim o uso da história da matemática configura-se em facilitar a aprendizagem do aluno em sala de aula, articulando como uma metodologia de ensino aprendizagem, propondo uma ordenação histórica, como uma maneira a constituir o ensino da disciplina de Matemática e a partir disso desenvolve nos discentes a capacidade de articulação da história e seu desenvolvimento de conceitos, formulas e aplicabilidades ao longo da jornada que deve ser inseridas como meio de motivação nas aulas de matemática. Para que ocorra esses fatos se faz necessário uma compreensão do aluno onde o mesmo deve relacionar os conteúdos matemáticos com o cotidiano para que assim seja despertado o interesse pela disciplina, e consequentemente ela se torne uma aprendizagem significativa.

Diante disso, desenvolvemos tópicos que possuem uma abordagem da história da matemática, onde possibilitem a compreensão da evolução do desenvolvimento humano junto a matemática, pois a mesma é de extrema importância para que haja entendimento das reflexões que serão feitas acerca do mesmo. A nossa metodologia está pautada em uma revisão de literatura acerca da utilização da história da matemática em sala de aula e em uma abordagem qualitativa, onde os autores como Miorim (2005) ressalta que a história da matemática trazida em contexto na sala de aula deve ser uma proposta metodológica como processo de ensino-aprendizagem, Brasil (1998) enfatiza que a história da matemática deve ser um recurso utilizado pelo professor para despertar nos alunos o interesse por conteúdos matemáticos, além de tratar de um recurso pedagógico implementado nas aulas de matemática, D’Ambrósio (2012) trata que a história da matemática possuem implicações importantes para o campo educacional, onde reforça que existem tendências metodológicas que atendem essa demanda no campo matemático, Lopes. \& Alves (2014) defendem as propostas de atividades em sala de aula onde o foco é a história da matemática, logo podemos observar que os mesmos defendem a utilização da história da matemática como estratégia de ensino em sala de aula. 


\section{Metodologia}

A metodologia para a realização da pesquisa acerca sobre A História da Matemática como instrumento de ensino e aprendizagem na educação básica, foi um estudo bibliográfico, tendo como caráter essencialmente qualitativo e está pautada em uma revisão de literatura acerca da utilização da história da matemática em sala de aula. Partindo também de uma revisão bibliográfica baseada em autores o como Miorim (2005), Brasil (1998), D’Ambrosio (2012), Lopes \& Alves (2014) em que os mesmos defendem a utilização da história da matemática como estratégia de ensino em sala de aula.

\section{Desenvolvimento}

A matemática apresenta grande importância em nosso meio porém a sua demanda de necessidade não surgiu apenas na contemporaneidade, desde dos nossos primórdios a matemática era utilizada, e muita das vezes até inconscientemente, pois a história da matemática se originou como descobertas matemáticas e através da sua evolução ao longo dos tempos; dos seus métodos e notações matemáticas cuja sua utilização foi uma continuação ao longo do tempo. Um aspecto relevante é que a matemática se desenvolveu em diferentes ambientes e culturas, mas que tiveram os mesmos resultados, apesar dos seus desenvolvimentos ocorrerem em épocas diferentes. É importante conhecer a história da matemática tanto para os professores quanto para os alunos, pois esse conhecimento nos ajuda compreender os desafios científicos ou tecnológicos surgidos ao longo dos séculos, onde a matemática a partir do seu desenvolvimento possibilitou a humanidade no seu processo de desenvolvimento.

Como a história da matemática é um campo que possibilita uma contextualização do professor com o seu conteúdo, assim a organização de abordagens pedagógica deve possibilitar no processo de ensino aprendizagem. D’Ambrosio (1999) afirma que, discutir educação sem recorrer aos seus registros históricos e referentes interpretações dos mesmos é impossível, valendo, para várias disciplinas, mas em especial, ao estudo da matemática. Miguel e Miorin (2004, p.53) acreditam ser possível através da história da matemática fazer com que os alunos entendam. Aprendizagem deve estar associada ao diálogo, a participação, à cooperação e à criação, e, não apenas à reprodução e a memorização, assim (Freire,1998) ressalta: “A educação é comunicação, é diálogo, na medida em que não é transferência de saber, mas um 
encontro de sujeitos, interlocutores que buscam a significação dos significados ", assim na História da Matemática deve haver essa transferência de saberes, logo um conteúdo com seu contexto histórico levará o aluno a um pensamento bem mais abrangente , proporcionando ao mesmo uma aprendizagem significativa.

Assim não se trata de oferecer apenas a história dos fatos e personagens ligados à Matemática, mas em se discutir que circunstâncias e necessidades levaram a se desenvolver determinados conceitos e cálculos e com isso associaremos a História da Matemática a problemas que pode ser uma opção interessante para aprimorar esse recurso, e ampliando assim sua função na ação pedagógica

De acordo com a Secretaria de Estado da Educação, nas Diretrizes Curriculares Estaduais (DCE), ao abordamos problemas da História da Matemática, o professor oportuniza aos discentes conhecerem determinado conteúdo, como campo de conhecimento que se encontra em construção possibilitando a aprendizagem dos mesmos, segundo DCE. A História da Matemática no ensino deve ter um espaço privilegiado, sobretudo, por possuir um grande valor motivacional para essa ciência. A prática pedagógica deve ser conduzida de modo a motivar os alunos, logo a tal motivação deve ser conseguida com a utilização de metodologias interessantes que devem ser inseridas dentro do assunto que será abordado.

Acreditamos que mesmo que o professor não seja um especialista em história da matemática para incorporá-la à sua prática pedagógica, no simples fato de compartilhar com seus alunos algumas informações ou curiosidades históricas a respeito de um tema estudado, o professor já estará - em alguma medida - incorporando a história da matemática às suas aulas.

Sendo assim, a história da matemática e sua interpretação tornam-se substancial na educação matemática, pois, a mesma, é essencial nas discussões sobre a disciplina e seu ensino. O professor poderá revelar, em sala de aula, a Matemática como uma criação do homem, levando, assim, seus alunos e encará-la como fruto da necessidade da humanidade. Despertando cada vez mais no aluno curiosidade sobre o que está sendo estudado, ponto forte e relevante para que os mesmos possam resolver e analisar problemas matemáticos.

No modo como Miguel e Brito (1996) entendem a participação orgânica da história da matemática na formação de professores, a história é concebida como uma fonte de problematização, contemplando as várias dimensões da matemática e da 
educação matemática. Assim nos leva a fazer com que os formadores de professores a discutir com seus alunos (futuros professores) as relações entre matemática e: cultura; sociedade; tecnologia; arte; filosofia da matemática; etc.

Temos ainda que a história da matemática, quando inclusa, nas atividades de ensino aprendizagem, de tópicos da história da matemática, permite obter um caráter construtivo e útil à aprendizagem dos alunos, assim pode perceber um caráter investigatório presente na geração, disseminação e organização dos tópicos ao longo do desenvolvimento histórico. (Mendes, 2003) Utilizando a mesma, podemos verificar que a matemática é uma construção humana, e por isso permite-se compreender a origem das ideias que deram forma à cultura.

Com a constatação que a história da matemática desempenha um papel decisivo, pois permite resolver problemas do nosso cotidiano, onde possui diversas aplicações no mundo do trabalho e funciona como instrumento essencial para o desenvolvimento da construção do conhecimento para outras áreas curriculares. Do mesmo modo, interfere fortemente na formação de capacidades intelectuais na aplicação do raciocínio dedutivo e na estruturação do pensamento do aluno.

Segundo Milies (2008), a matemática conhecida hoje, acabadas e elegantes, foi o resultado de desafios que os matemáticos enfrentaram, é necessário mostrar aos alunos que eles também podem ser matemáticos, e que, ao enfrentar seus desafios, podem também criar sua própria matemática.

A própria matemática, como dita anteriormente, é uma proposta metodológica que permite ao aluno descobrir a gênese dos conceitos e métodos que aprenderá em aula. Em outras palavras este enfoque permitirá ao aluno fazer relação das ideias matemáticas desenvolvidas em sala de aula com suas origens, e mostra como ela foi construída como resposta e perguntas provenientes de diferentes origens e contextos, motivados por problemas de ordem prática, bem como problemas relacionados a investigação internas à própria matemática, ou história da matemática.

Miguel e Miorim (2005) enfatizam que pode-se buscar na história da matemática:

[...] apoio para se atingir, como os alunos, objetivos pedagógicos que os levem a perceber, por exemplo:

(1) a matemática como criação humana; (2) as razões pelas quais as pessoas fazem matemática; (3) as necessidades práticas, sociais, econômicas e físicas que servem de estímulo ao desenvolvimento das ideias matemáticas; (4) as conexões existentes entre matemática e filosofia, matemática e religião, 
matemática e lógica , etc.; (5) a curiosidade estritamente intelectual que pode levar a generalização e extensão de ideias e teorias; (6) as percepções que os matemáticos têm do próprio objeto da matemática, as quais mudam e se desenvolvem ao longo do tempo; (7) a natureza de uma estrutura, de uma axiomatização e de uma prova. (MIGUEL E MIORIM,2005, p.53)

Diante disso podemos considerar que a História da Matemática no processo de aprendizagem, deve haver uma ênfase na mesma, pois vem como um recurso a viabilizar e facilitar a aprendizagem de conteúdos matemáticos, com suas abordagens históricas, onde associar a história da matemática a problemas pode ser uma opção o tão quanto interessante para aprimorar esse recurso, ampliando sua função na ação pedagógica. Com base nessas considerações e com a concepção de Mendes (2003, p.97) a História da Matemática deve ser utilizada principalmente na construção das noções básicas de conceitos matemáticos, permitindo que o aluno possa participar da construção do conhecimento.

\section{Conclusão}

O presente trabalho buscou apresentar uma forma de estudo e utilização da História da Matemática como instrumento de ensino e aprendizagem na educação básica. Assim por meio da história da matemática é possível perceber que a matemática que estudamos hoje percorreu um longo caminho na história da humanidade, passou por várias fases, com seus problemas sociais, sua filosofia de vida, religiões, crenças, cultura e arte, suas preocupações, necessidades práticas e abstrações; espaços geográficos onde as civilizações se desenvolveram, lutas territoriais, entre outros.

Por um lado percebe-se que a organização da disciplina deve buscar a interdisciplinaridade e a contextualização para desenvolver o aluno de forma mais completa possível. Apoia-se essa consideração em D’Ambrosio (1996, p.09), em que ele propõe "orientar o currículo matemático para a criatividade, para a curiosidade e para crítica e questionamento permanentes, contribuindo para a formação de um cidadão na sua plenitude e não para ser um instrumento do interesse, da vontade e das necessidades das classes dominantes".

Ou seja, é possível o professor usar de sua criatividade e trazer para aula situações cotidianas em que a matemática é utilizada e também mostrar de onde surgiram esses conceitos e como foram formados ao longo dos tempos para que a matemática deixe de ser a "vilã" do currículo escolar, propiciando assim um cenário que 
A história da Matemática como instrumento de ensino e aprendizagem na educação básica.

Andréia Nunes dos Santos e Juciane de Sousa

aproxime os estudantes dessa ciência e consequentemente acabe facilitando o processo de ensino aprendizagem, bem como de formação crítica de cidadãos.

\section{Referências}

BRASIL. Ministério da Educação. Secretaria de Educação Fundamental. Parâmetros Curriculares Nacionais: matemática. Brasília: Mec, 1998. $3^{\mathrm{a}}$ e $4^{\mathrm{a}}$ ciclos.

D’AMBrosio, U. ; BALESTRI, R. D. A participação da História da Matemática na formação de professores de Matemática na óptica de professores/pesquisadores. Disponível em: . Acesso em: 11 jan. 2020.

D’AMBROSIO, U. Educação Matemática: da teoria á prática. Campinas, Papirus, 2012.

FREIRE, P. Pedagogia da Autonomia: saberes necessários á pratica educativa. 7. Ed. São Paulo: Pag e Terra, 1998.

MENDES, I. A. História da matemática: um enfoque transdisciplinar. In. XICIAEM. FURB. Blumenau: Furb, CD-CARD,2003.

MIGUEL. A; MIORIM, M.A . Historia na educação matemática : propostas e desafios. Belo Horizonte: Autêntica, 2005.

MIGUEL, A; BRITO, A. de. J. A historia da matemática na formação do professor de matemática. Cadernos CEDES. Campinas: Papirus, P.47-61, 1896.

LOPES, L. S; ALVES, A.M.M. A historia da matemática em sala de aula: propostas de atividades para a educação básica. In: Encontro Regional de estudantes de matemática da Região Sul- EREMAT, 20. ,2014, Bagé. Anais eletrônicos ... Bagé: UNICAMP, 2014.

ROQUE, A.C.C. Uma investigação sobre a participação da história da matemática em uma sala de aula do ensino fundamental. 2012. Dissertação (Pós-Graduação em Educação), Universidade Federal de Minas Gerais.

SANTOS, C.A.; D’AMBROSIO, U A História da Matemática como Ferramenta no Processo de Ensino-Aprendizagem da Matemática. 2007. Dissertação (Mestrado Profissional em Ensino de Matemática), Pontifícia Universidade Católica de São Paulo.

VIANA, M.C.V. e SILVA, C.M., Concepções de professores de matemática sobre a utilização da história da matemática no processo de ensino-aprendizagem.

BARONI, R. L.S. e BIANCHI, M. I. A História da Matemática como recurso didático. In: PACHECO, E. R. e VALENTE, W. R. (orgs). Coleção 20. 